Paideusis

\title{
Education, Culture and Epistemological Diversity: Mapping a Disputed Terrain (Claudia W. Ruitenberg \& D. C. Phillips (Eds.))
}

Linda Overing

Volume 21, Number 2, 2014

Working Compassion

URI: https://id.erudit.org/iderudit/1071568ar

DOI: https://doi.org/10.7202/1071568ar

See table of contents

Publisher(s)

Canadian Philosophy of Education Society

ISSN

0838-4517 (print)

1916-0348 (digital)

Explore this journal

Cite this review

Overing, L. (2014). Review of [Education, Culture and Epistemological

Diversity: Mapping a Disputed Terrain (Claudia W. Ruitenberg \& D. C. Phillips

(Eds.))]. Paideusis, 21(2), 80-84. https://doi.org/10.7202/1071568ar 


\section{Education, Culture and Epistemological Diversity: Mapping a Disputed Terrain}

by Claudia W. Ruitenberg \& D. C. Phillips (Eds.), New York: Springer, 2012

\section{LINDA OVERING}

Concordia University

Multiculturalism in the Classroom; Minority Status and Learning; Diversity in the Classroom-these are titles of courses offered at both the undergraduate and graduate levels within the Department of Education of one urban Canadian university. As a student, teaching assistant, and facilitator of these particular classes, I have read and heard all manner of claims for the different ways of thinking, believing, and knowing apparently exercised by the diverse populations in our schools and larger societies. It was, therefore, with great curiosity that I embarked on this review of Education, Culture and Epistemological Diversity: Mapping a Disputed Terrain, edited by philosophers of education Claudia W. Ruitenberg and D.C. Phillips (2012). Together with contributors Jon A. Levisohn, Lorraine Code, Harvey Siegel, and Lynda Stone, they tussle with the overarching question: "In a multicultural society, what do claims about "epistemological diversity" amount to, and what is gained and what is lost when these claims are made using epistemological language" (p. 2)?

Before delving into the claims and challenges that are the subject of the text, however, I believe that it is important to make two points of clarification about what Ruitenberg and Phillips are not doing. Firstly, they are not defending the barricades of an epistemological 'closed shop' that denies entry to fresh ideas and critical debate. In the introductory first chapter, Ruitenberg and Phillips point out that legitimately philosophical claims for "alternative epistemologies" do arise and have been seriously considered. Over the past two decades, for example, debate has centred on the possibility of a "feminist epistemology" improving upon or replacing the traditional, "androcentric" model. Secondly, neither they nor any of the contributors are denying the seriousness of the sociopolitical issues of marginalization and hegemony put forward by multiculturalists. "The question raised in this volume...is why these political issues are frequently couched in epistemological language" (p. 9), thereby possibly obscuring the "real nature" of these concerns, not to mention the "real nature" of epistemological inquiry.

What is up for examination in this collection of essays are the broad claims made within the context of education for alternative epistemologies. These assertions cover a terrain from the unique "truth" claims of methodological paradigms, to the specific "knowledge" teachers have of their subject matter, to the diverse "ways of knowing" employed by cultural and ethnic groups. It is these latter claims in particular that are interrogated by the contributors, and the editors further refine the focus: (1) What is meant by the claim that cultural groups have their own specific epistemologies, and how are these claims justified; (2) Are the knowledge claims that flow from these unique epistemologies tenable; (3) By being framed in epistemological terms, do very important sociopolitical issues become blurred?

What, exactly, is being (mis)claimed in the name of epistemology? Phillips sets the overarching context of the discussion in Chapter 2, with a critical review of the theoretical work

(C) Copyright 2014. The author, Linda Overing, assigns to Paideusis the right of first publication and educational and non-profit institutions a non-exclusive license to use this document for personal use and in courses of instruction provided that the article is used in full and this copyright statement is reproduced. Any other usage is probibited without the express permission of the author. 
of those he terms the "“frontline" advocates for "multicultural epistemology"-members of the broad educational research community, curriculum experts, sociologists, and the like-who believe that different cultural or ethnic groups have different epistemologies" (p. 11). These works are chosen on the basis of their formative and ongoing influence on what continues to be a very lively debate. In each analysis, Phillips points to questionable uses of philosophical terminology and concepts, while nonetheless marking the sociopolitical importance of many of the claims. Three recurring difficulties emerge: the conflation of "belief" and "knowledge;" the advocacy of questionable criteria of warrant; and, the misrepresentation of sociopolitical concerns as epistemological ones.

Banks' (1993) working definition of knowledge is one illustration of the first of these issues: “...the way a person explains or interprets reality.... [which] includes ideas, values and interpretations..." (as cited in Ruitenberg \& Phillips, 2012, p. 15). Although he is in agreement that all of us explain or interpret reality to some degree based on these criteria, Phillips argues that Banks makes the very common error of disregarding the epistemological distinction between those beliefs and the critically justified and strictly judged beliefs that constitute knowledge.

Areas of Collins' (1990) work are characterized as representative of the types of sociopolitical arguments often made in the name of epistemology. Because of the sustained dominance of white male interests and standpoints, she argues, those of black women have been subjugated. In response, Collins asserts, African-American women have developed distinctive ways of producing and validating knowledge, stemming from the standpoint of "concrete personal experience as a criterion for credibility," and employing dialogue and connectedness in assessing knowledge claims (as cited in Ruitenberg \& Phillips, 2012, pp. 19-24). These, Phillips argues, constitute some of the essential processes of knowledge production, but do not meet the requirements for the critical assessment of knowledge claims; they belong within the territory of politics, sociology, or sociology of knowledge.

It is one of the attractive features of this book that the elements of a live debate are compellingly played out. Ruitenberg's responsive critique immediately follows Phillips' literature review, rather than forming its own chapter. Singling out Phillips' treatment of Collins' (1990) chapter, Ruitenberg concedes the sociological basis of Collins' arguments, but contests its easy dismissal by questioning, "to what extent the sociology of knowledge can be kept separate form the philosophy of knowledge" (p. 35). For example, she argues, Longino (2002) — “an epistemologist well respected by Phillips" (p. 35)—suggests that a socioepistemological approach to scientific knowledge might hold the promise of "contextuality of justification, interdependence of cognitive agents, and (possible) plurality of content" (as cited in Ruitenberg \& Phillips, 2012, p. 35), as parts of a normative epistemological project. This seems somewhat similar to Collins' position involving concrete experience and community dialogue. In Longino's model, inclusive, critically discursive community interactions assure "that what is ratified as knowledge has survived criticism from multiple points of view" (p. 36). What remains a crucial condition, therefore, is that the "knowledge" must be tenable.

In Chapter 3, Levisohn and Phillips expand on one of the major concerns raised by Phillips in the chapter before: What happens when the language of epistemology is used by multiculturalists and philosophers of education to advance political, sociological or curricular arguments? Why does it matter? Presenting a 'Map of Multicultural Epistemology,' they attempt to chart the dangerous reefs and terrain of terminological misuse and conceptual misrepresentation. This is an important moment in the book as it provides the clearest articulation and sharpest delineation of traditional epistemological boundaries.

Levisohn and Phillips establish two essential sets of distinctions to guide us on our inquiry route. The first defines the traditional meaning of the term "epistemology" as used in philosophical inquiry: the theory of knowledge, how knowledge claims are validated, and establishing the line "between the set of beliefs which individuals actually hold and the subset of those beliefs that are well justified on the basis of sound and critical inquiry" (p. 40 ). 
The second set clarifies the essential differences between normative and descriptive inquiries. As a normative field of inquiry, epistemology has (a) stood as a "meta -discipline" directing the establishment of standards of warrant that distinguish knowledge from belief, and the judgment of knowledge claims based on those standards. These criteria are numerously represented by incommensurable normative theories of knowledge (b), such as empiricism, positivism, or pragmatism. Descriptive accounts of epistemology involve how people acquire beliefs (c), and what these belief sets are (d).

Levisohn and Phillips contend that when these sets of distinctions are blurred-for instance, in the way that Phillips illustrates in the second chapter- "then all rational argument is potentially undermined, including the very arguments that the supporters of multiculturalism wish to employ in order to advance their cause" (p. 42). To illustrate their point, each of the classes of epistemology is thoroughly examined, referencing selections from some of the representatives of epistemological diversity introduced in Chapter 2, who draw a connection "between some aspect of personal identity-culture, ethnicity, race class or social status, sexual orientation, gender-and what counts as knowledge" (p. 43).

Siegel continues the appraisal of claims of epistemological diversity in Chapter 4, with a particular focus on clarifying the way that these claims influence education research and graduate education. Siegel's most original contribution to the book's collection lies in how he moves from his concise treatment of the various interpretations of epistemological diversity to the question of whether it is presumptuous to criticize the epistemology of a particular community of practice/approach to research/subordinated group. Not surprisingly, Siegel maintains that all epistemological claims should be subjected to criticismotherwise, how make the move from claim to knowledge? How distinguish the sociopolitical from the epistemological? - and insists that the same "neutral and objective" standards can and should be applied in every case. Within the context of research, this critical evaluation would involve questioning the effectiveness of research methods to produce reliable, warrantable conclusions, based on "evidence sufficient in quantity, quality, and variety" (p. 7). To apply less stringent justificatory requirements to "other" perspectives would itself be morally suspect, according to Siegel, as it would unjustifiably accord to these particular claims and claimants less respect than that given to their epistemological relatives. Concerning the potential for the exercise of power in the act of critique, Siegel insists that critique is not in and of itself a hegemonic tool; however, critique that "does not stand up to critical evaluation but is rather a matter of inappropriate imposition" (p. 80) certainly is. He insists that argumentation and justification of warrant "by way of appeal to legitimate criteria, locally and neutrally applied" (p. 80) are the best possible means to combat hegemonic discourses.

Siegel's insistence on the possibility of relying on neutral criteria of warrant comes right up against Code's insistence, in Chapter 5, "that necessary and sufficient conditions for establishing empirical knowledge claims cannot be found, at least where experientially significant knowledge is at issue" (p. 98, emphasis added). How, then, does epistemological inquiry proceed? Code proposes a "constructivist reorientation" that takes factors pertinent to the circumstances of the subject "centrally into account in evaluative and justificatory procedures" (p. 90). She suggests that there are more urgent questions for epistemology to address than criteria of evidence, justification, and warrantability. These include the subjectivity of the inquirers: "their interests in the inquiry, their emotional involvement and background assumptions, their character...their material, historical, cultural circumstances" (p. 92)—their standpoint. Most subversively, however, Code argues that in order to achieve empirical adequacy, feminist critique should act as an "experimental control" in "case-by-case analyses of the political and other structural circumstances that generate projects and lines of inquiry" (p. 97).

In Chapter 6, Ruitenberg addresses the ubiquitous presence of the phrase "ways of knowing," which is frequently used to differentiate between culturally diverse epistemologies within the multicultural context. Ruitenberg examines the usage intentions and possibilities, suggesting that in some cases the phrase is employed "as trope for worldviews" (p. 102) in order 
to convey "a set of beliefs about why and how the world and everything in it is the way it is" (p. 112), that has little to do with knowledge. Sometimes it is used to position authors "explicitly outside of and even in opposition to traditional western epistemologies and their metaphysical underpinnings" (p. 115). Yet other times, it is quite straightforwardly used to refer to knowledge such as "knowing history."

Ruitenberg is particularly intrigued by the distinctive ways in which "knowing" is used to differentiate between propositional knowledge, and knowledge with a direct object (p. 117), that is, "ways of knowing about the world," and ways of "knowing the world" or "knowledge by acquaintance." These terms are more finely articulated by the French words, savoir (to know in a propositional or procedural way) and connaitre (to be acquainted with someone, something, or somehappening); these are fine distinctions in the English language, and Ruitenberg spends considerable time refining the articulations of "knowing," referencing Robinson (1971) and Hirst (1975).

Clearly, Ruitenberg's main concern about "ways of knowing" lies in the intention and "the effects of the use of this phrase" (p. 110), which brings us around full circle to the original query that the text poses: What is meant by the claim that people "know" in different ways based on their geographical locations, historical or cultural backgrounds, gender? Appropriately, the roundtable chapter, a transcription of discussions between Ruitenberg, Phillips, Siegel, Code and Stone that took place before the book was finalized, reiterates this concern. It also, however, picks up on a theme that is referred to but not discussed in depth in the text, concerning the pedagogical purpose of the book: "How do we educate our future researchers?"

Early in the conversation, Stone invites the other contributors to keep in mind the audience for the discussion and the book: graduate students and their professors. She points to the need for sensitivity to claims made by graduate students about their own "culturally determined ways of knowing", while also acknowledging the need to give them "the kind of language and philosophical distinctions that can be useful" (p. 124) in classroom and research contexts. Ruitenberg comments on the cursory and superficial way in which epistemology is discussed in graduate classrooms, and usually only within the narrow context of research methodologies. Later in the debate, she asks how we are to constructively respond to students who "want to claim a different kind of epistemology, one in which the fact that my body tells me so is ground for knowledge" (p. 135). How, she asks, can we work to have a better conversation about what might or might not count as epistemology? Getting the last word in, Siegel makes the grand statement concerning multicultural epistemologies: "I think we should just call it like it is: They're not epistemologies. If students don't understand that by the end of their graduate education, they haven't been well-educated" (p. 138)!

I'm sure that this statement will get a rise out of many a student, professor, and theorist, making for lively debate, and it speaks to Ruitenberg's and Phillips' reflections on pedagogy in the Epilogues that follow the roundtable. Ruitenberg points to the significantly different ways in which philosophers and educational researchers talk about epistemology, and draws on this difficulty to suggest the need "to (re)introduce philosophical discussions of epistemology in the preparation of future educational researchers" (p. 139). At present, she says, when epistemology is discussed in graduate classes, it is in the limited terms of research methodology. She conjectures that the mis-use of "epistemology" is an indication of "misrecognition" resulting from insufficient grounding in philosophical issues. With a dash of pessimism, Phillips reinforces Ruitenberg's concerns, but questions the ability of education professors, themselves often "philosophical neophytes," to successfully convey the "extremely tricky epistemological" concepts that would help students to make the kinds of distinctions necessary in the context of multicultural complexity (p. 142).

So, students who do not recognize the non-philosophical nature of claims to multicultural epistemologies have been badly educated, and professors of education are ill equipped to address this problem. Against these limitations, the well-intentioned but misguided 
influence of the frontline advocates for multicultural epistemology continues to hold great sway, and the possible misrecognition and misapplication of epistemological terms and concepts proliferates. Given these conclusions, how are we meant to proceed? It is, of course, beyond the stated mandate of this collection to prescribe future practice. I would, however, have liked some small indication of what, according to Siegel, good and philosophically well-grounded research education would look like, and how, by Ruitenberg and Phillips' judgment, professors' philosophical teaching skills might be more sharply honed, in order to better the abilities of all to grapple with these very complex issues. That being said, I would also suggest — with one caveat - that the roundtable discussion, particularly, could provide the perfect point of entry to the type of philosophical discussions one might envision as one means to this end. The subject matter is familiar to any student and professor involved in educational studies, and the very fact of an ongoing debate may invite participation within the typical graduate seminar setting.

Another outstanding issue concerns Phillips call for "sensitivity to the concerns raised by those who are pointing out that cultural diversity issues are largely invisible in the way epistemology currently is pursued" (p. 155). Earlier in the text, Levisohn and Phillips assert that "we all play by the same normative epistemic rules" (p. 61, emphasis in text). In the context of the "strictures," "scrutiny and criticism" of the type of "scholarly argument" engaged in by the roundtable participants, what might sensitivity look like? Debates like this have traditionally taken place on terrains that require powerful and powerfully supported voices engaged in strong debate according to rigid rules of skirmish. Marginalized people and groups-including, as pointed out by both Ruitenberg and Stone, students_-often lack these skills of contestation as a very direct result of their marginalization; or, are culturally undisposed to pursue knowledge in this confrontational manner, however respectful it might seem to those more culturally disposed to this format. Perhaps "sensitivity" requires the recognition that claimants to diverse epistemologies may be rightfully challenging the very language, nature and manner of justificatory processes in order to gain entry into a conversation from which they have been previously excluded.

As mentioned above, in Chapter 2, Ruitenberg directs our attention to the possibilities offered by Longino's (2002) alternative justificatory model in which inclusive community interactions might lead to the ratification of knowledge claims from multiple points of view. This process would "involve both traditional evidential norms and the community norms of effective critical interaction" (as cited in Ruitenberg \& Phillips, p. 35). The possibilities suggested by this "social epistemology" perspective call for further investigation: Might the normative epistemic rules and language change? If so, in what ways? What beliefs might be acknowledged as justified beliefs when dominant and subordinate cultures engage in conversation on an equitable epistemological terrain? What knowledge claims might be reduced to unsupported beliefs when discussed by a diversity of stakeholders in an open forum?

I raise these issues more in response than as critique. In Education, Culture and Epistemological Diversity, Ruitenberg and Phillips set out to map the disputed terrain of a philosophical debate, and with the collaboration of their co-contributors and the choice of included theoretical sources, they do just that. This collection of essays represents an important and ongoing philosophical conversation that invites graduate student researchers and professors to equip themselves to engage with, and respond to questions about cultural beliefs and un/warranted knowledge claims.

As Ruitenberg and Phillips clearly state in their joint introduction to the text,

...the crucial point is, the issues here have not been settled, and have been the subject of lively debate in the philosophical and educational literature for a considerable period of time; we wanted this book to convey the liveliness, openness, and even confusion that exists when a live issue is being explored" (p. 1).

In this, they succeed. 